\title{
Effect of physical development on urban communities using a strategic planning process and its implementation
}

\author{
M. A. Abd El-Wahab ${ }^{1}$, Y. A. Azzam² \& H. A. Ayad ${ }^{2}$ \\ ${ }^{1}$ Department of Architecture, Pharos University, Alexandria, Egypt \\ ${ }^{2}$ Department of Architecture, Alexandria University, Egypt
}

\begin{abstract}
This paper mainly explores the effect of physical development on urban communities using strategic planning methodology. Strategic planning in Egypt is a set o f steps that is applied in a system to achieve a set of documents and strategic policies to function in a definite period of time. This planning method has been widely used over the past years in Egypt in order to address fundamental key issues in the Egyptian city and develop planning techniques.

Governments are resp onsible for developing framework policies that both initiate and guide the decision-making process, setting the proper conditions for effective regional and local planning, to suit the country in which these process are applied in, but one of its frameworks is strategic planning which is faced with two main problems while conducting it:

1) The urban community problems;

2) The implementation of these planning strategies.

So the output of such process should be much more than merely a plan document or a vision statement, but has to be real life solutions valid to raise the life style of the Egyptian people, accommodating a rapidly growing population, providing them with adequate infrastructure network and shelter while ensuring sustainability in addition to enhancing economic growth. Going through the guidelines of the planning system in Egypt and $\mathrm{c}$ oncluding the paper with the case study of R ashid city strategic planning process, its implementation system and, so far, the obstacles facing it.

Keywords: strategic planning, planning, urban communities, cities, implementation, Egypt, Rashid, national planning, regional planning, GOPP.
\end{abstract}




\section{Introduction}

Egypt has been on the track of reforming its planning system, sponsored by the General Organization for Physical Planning (GOPP). The GOPP was aiming on developing four main axes: 1) R e-planning and developing the current construction. 2) Planning and developing new desert areas. 3) Urban development projects for Greater Cairo Region. 4) Infra-Structure projects. The GOPP shifted the planning system from the conventional master plan, which is top down and expert led (UN-Habitat [1]) towards the strategic urban plan, which is a public-sector-led and socio-spatial focus (de Graaf and Dewulf [2]). Preparing SUPs for the Egyptian cities is integrated under it the upgrading of slum and Deteriorated areas, prep aring SUPs for villages and preparing integrated strategic development for governorates (GOPP [3]).

The main objective for this paper is explaining the strategic planning process in Egypt analyzing it briefly on the national, regional and local level. Clarify the case study of Rashid city; one of most popular cities in Egypt in addition that it's the strategic plan that has won the second prize of the Organization of Islamic Capitals and Cities in its 8th session in the field of Regional Planning and Urban Development. Using the SWOT analysis system to know the weak and strong spots of the city, and by comparing it with the sustainable aspects in order to identify at the end if the strategic planning process applied in Egypt is clo se enough to the sustainable planning or not.

\section{Development strategies at a national level in Egypt}

This part deals with strategic plans that have been prepared on the national level in order to identify deficiencies in different key sectors and most importantly the shelter sector, housing and slum areas and the economic development sector and infrastructure sector, which covers all of the road networks, transportation and traffic, water networks, sanitation, electricity, energy and telecomm unications networks -where those schemes were set up in the year 2008 and 2011 - need to fill the current deficit and to id entify their locations on the national level, in addition to providing future requirement and provide social justice between regions of the Arab Republic of Egypt as well as maximizing the role of Egypt and the m utual influence between it and other countries on $t$ he Arab and international levels.

\subsection{The objectives of the National Spatial Strategy}

The objectives of the National Spatial Strategy can be imagined as a set of basic themes of the National Development Strategy as follows:

- The full mobilization of productivity energies and optimum use of national resources to achieve comprehensive development (maximizing GNP).

- Maintain the resou rces of wealth, rare or non-renewable resources suc $h$ as energy and water resources, the preservation of agricultural land in the Delta and 
the narrow strip of the Nile Valley and directing the urban movement towards desert areas.

- Reduction of economic and social inequalities between the region and mitigate the urban phenomenon of urban polarization of Cairo and Alexandria and highly concentrating on economic activities.

- Developing the desert areas for strategic and developmental considerations.

- Contributing to correct the imbalance between population growth and spaces inhabited ground.

- Strengthen the competitiveness of the national economy towards foreign markets to promote production and trade centers with the comparative advantages and competitiveness in various regions of the Republic, In addition to obtaining a set of constitutional policies - nationally, regionally, urban and rural policies.

\section{Development strategies at a regional level in Egypt}

The strategic plans at regional level in the Arab Republic of Egypt are another level of planning in the 7 regions which are: Greater Cairo - Alexandria - Suez Canal - Nile Delta - N orth Upper Egypt - A ssiut - South of Upper Egypt (Fig. 1). The methodology used for each region depends on the characteristics of each of them, the evaluation of strate gic plans and re gional plans by studying each region should be according to the following order:

A - Each region should be recognized in terms of natural features and administrative features of population and urban features.

B - Economic and features that address the study of the labor market and the economic base for each region.

$\mathrm{C}$ - The natural and physical res ources of the region include natural and land resources, urban and infrastructure.

D - Examine development strategies for each region with surrounding features of the strategy and policy development sector.

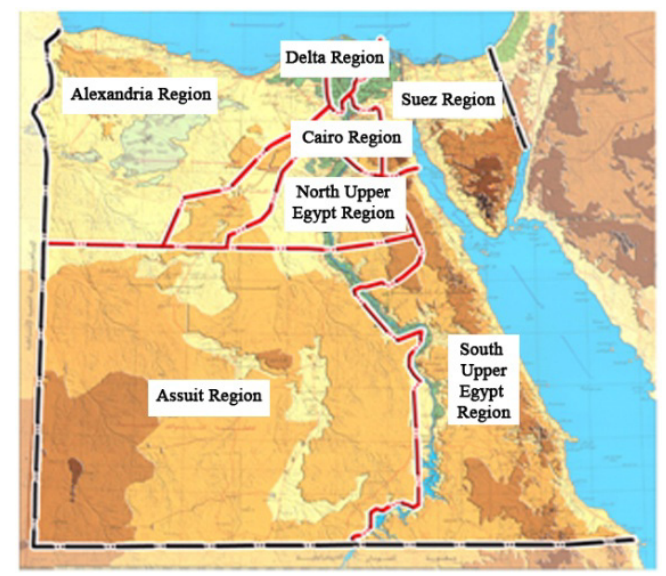

Figure 1: Regional division of Egypt (GOPP [4]). 


\section{An applied study for preparing the overall strategic plan to develop Rashid city}

As new approaches of urban planning emerge, where Egypt is currently on the track to reform its planning system, Preparing Strategic Urban Plans for the Egyptian cities on the national level has been carried out since 2007. It is carried out on two levels. One targets larg e and medium sized cities, while the other targets small cities. The former is fully sponsored by GOPP, while the latter is a mutual cooperation between the GOPP and UN-Habitat. Through a participatory process, local stakeholders are in volved in preparing a strateg ic urban plan, which should provide a ro ad map for developing their city for the next two decades (Khalifa [5]).

\subsection{The reason for selecting Rashid city}

Based on the general policy adopted by the government in preparing the strategic public and detailed plans for Egyptian cities, wh ich are prep ared by th e consultancy offices registered in GOPP, the organization works under the Ministry of Housing, Utilities and Urban Development. Given that the strategic and detailed plan of Rashid City, until in 2027 has obtained an award from the Organization of the Islamic cities an d capitals in the year 2011, so first we review the preparatory phase and study the basic features of the city of Rashid, then the future vision of Rashid city is p resented, and in the last phase of the study the detailed and the executive action plans is allocated.

Rashid city is located on the west bank at the mouth of Rosetta branch on the Nile, approximately $65 \mathrm{kms}$ north-east of Alexandria and $55 \mathrm{kms}$ away from Damanhur city. The total area of Rashid center is $191.98 \mathrm{~km}^{2}$, equivalent to about $11.2 \%$ of the Behaira province area, as for the area of Rashid city it is $\mathrm{u} p$ to $5.04 \mathrm{~km}^{2}$, equivalent to about $6.2 \%$ of the total area of Rashid center, the urban area of is about $3.2 \mathrm{~km}^{2}$, and the city border reaches up to about $3.65 \mathrm{~km}^{2}$, which covers about 870 acres. The Northeast side for Rash id center is represented in the Rosetta branch, while the Mediterranean represents the North West limit, as for the South-west Bank Edco is located, while Mahmudia branch and Abu Homs centers Limit Rashid center in the south (GOPP and EHAP [6]).

\subsection{The preparatory phase and study the basic features of Rashid city}

The first phase for pre paring the strategic plans for cities and large urban agglomerations is the study of the basic features of the city through five main axes, starts with the regional entrance and institutional framework for Rash id city. Then the population and construction studies of the city, also the study of the local economy is considered the m ost important aspect, while the fourth axis identify ways to supply infrastructure and facilities to the city, Finally the basic features study concludes with the fifth axis assigned to the current public services study in Rosetta city (Fig. 2). 


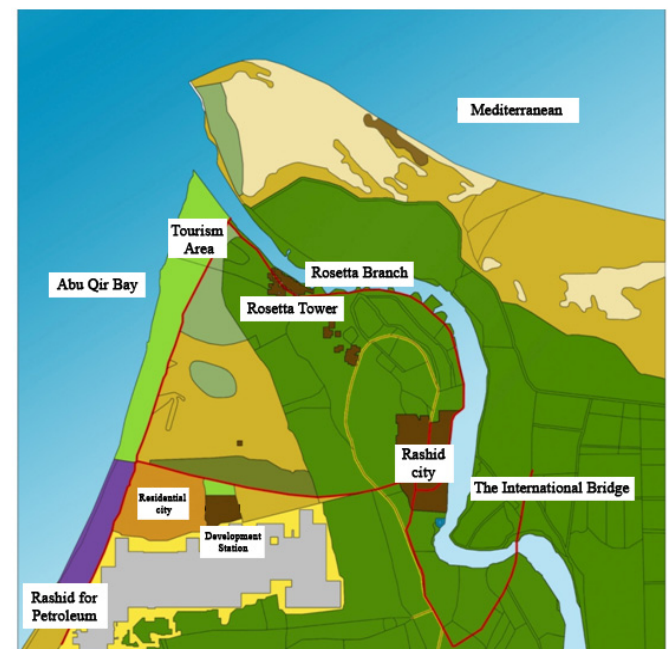

Figure 2: The relation between Rashid city an d Rashid center (GOPP and EHAP [6]).

\subsection{The regional entrance and institutional framework of Rosetta city}

Rashid center consists administratively of 3 rural units division and 15 major villages. The city of Rashid has great importance on the province and the regional level where it gains its importance from its strategic location, also the River Nile and the Me diterranean Sea are joined at the Boughaz, so Rashid is blessed by this unique location at the regional level of Alexandria, this must be put into consideration when developing the overall strategy for the development of center and the city of Rashid.

The development of roads in the range of Elbehaira province and Alexandria region, is of a fundamental importance for the future development plan of Rashid's center and city, where the international road represents a great strategic importance in linking tourism between the cities of Rosetta and Alexandria activating per day tourism, especially after the establishment of the international road link Rashid became in close proximity to Alexandria in time (40 minutes).

Rashid location at the province and the regional level maximize its role in terms of tourism owing to being the second city after Cairo due to the number of Islamic monuments in addition to its special strategic location.

\subsection{Urban and population studies of the city}

The population of the town of Rosetta in 2006 was about 69,827 people representing about $7.7 \%$ of the total urban population of Elbehaira province and about $36 \%$ of the total population Rashid center, the annual growth rate of the city population has reached $2.8 \%$ during the period $1976 / 1986$ and dropped to $1.1 \%$ during the period $1986 / 1996$ and then rose to $1.8 \%$ during the period 1996/2006. 
The demographic study estimates that the city population will become 78,572 people in 2012 accordi ng to the altern ative and 99,883 people in 2027 , al so emigration factors is exp ected to con tinue from the city to the urban areas of other provinces, due to lack of available necessary investments to create jobs to absorb excess labor resulting from population growth, with an est imated net migration of about 7109 people during the period 86/1996 and about 2730 people during the period $96 / 2006$, that is to say that the city has lost this many during that period.

As for economic study, it is expect ed from an economic perspective that the population will reach about 132 thousa nd inhabitants in 2027, if the estim ated development rates of various economic sectors are achieved, so the city can be transformed from being a repellent to the residents to an attractive city.

The average family size in Rashid city, has dropped from 4.4 persons/family in 1996 to 4 per son/family in 2006, due to low birth rate, while the number of family increased to around 4345 families during the same period, and it is expected the decline to continue in family size to 3.6 persons/family in 2027 , and that the number of families to 27,745 family, with an in crease of 8102 families during the period from 2006 to 2027.

\subsection{Local economic study for Rashid city}

It has a huge potential regarding tourism activities, it's a lso rich with natural, archaeological resources, religious Islamic, Coptic monuments, and therapeutic, recreational marine and Nile resources, but nevertheless it is characteri zed by modesty of $\mathrm{t}$ ourism infrastructure, poor care of $\mathrm{m}$ onuments, and lack of appropriate tourist services. The tourism sector as $\mathrm{m}$ ultiple forward and backward linkages with most other economic sectors such as industry, services, agriculture and construction, in addition to direct employment in hotels, restaurants, cafes transport, recreational, cultural, and other facilities (Fig 3).

The tourism activity in the city represen ts $3.8 \%$ of the total economic activities as measured by the number of workers in this sector in 2006, with a coefficient of resettlement tourism activity in the city $5.4 \%$, making it a $p$ ilot activity, with an estim ated gross t ourism in $2006 \mathrm{t}$ hat reached 21.2 million pounds, the increase in gross tourism during the period 2006 to 2027 is estimated at about 66.9 million pounds, with an esti mated additional employment generated by tourism activity during this period, a number ranging between 2604 and 3507 jobs with an average of 146 job opportunity a year.

The palm sector is on e of the promising sectors in Rashid city, with the wealth of about a million palm trees, representing $10 \%$ of the total palm trees in Egypt, with estimated date production about 18 million pounds annually, and this sector can contribute to several industries such as packaging, refrigeration, jam industry, conservation, and the production of good types of honey, to improve the industry of palm leaves, cages, some furniture and industry of fiber cords, palms can also be exploited within the tourism development plan, with an estimated additional number of jobs that will be provided after the development of this sector by about 958 new jobs during the period from 2006 to 2027. 


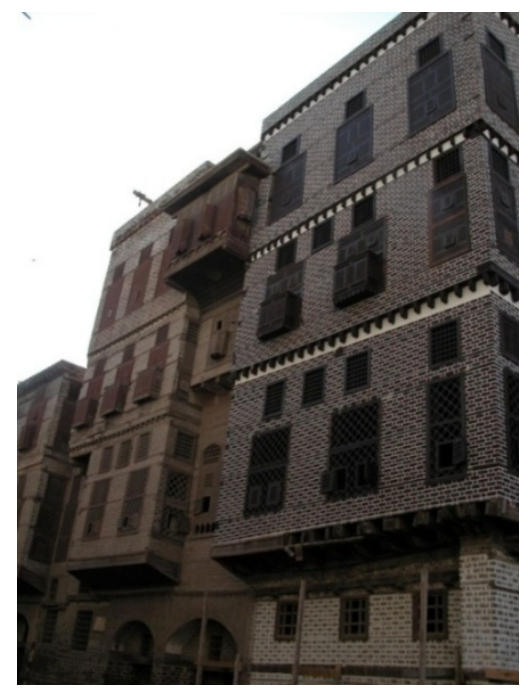

Figure 3: Ramdan and Gamal historical house.

Fishing is one activity that characterizes the city of Rashid, where it has the natural recourses, a large number of fishing boats estimated to about 450 boats, 22 fish farms, and a large number of fish cages, that produces about 400 tons of fish annually, where a large part of it is exported to the Gulf States. Number of fishing employees are estimated at about 1077 workers, representing $4.9 \%$ of the total workers in Rashid in 2006 the endemic factor of this activity is 2.6, making it a leading activity. Fish production is estimated to reach 93 million pounds in 2027, the estimated employment opportunities will be provided after the plan about 2352 new jobs during the period from 2006 to 2027.

To develop the fish production Rashid Port and its integration with the fishing port of Elmaadia, it also needs trained labor, mechanization of the ships, and upgrading the equipments, so as $\mathrm{t} \mathrm{o}$ increase the capa city of this $\mathrm{s}$ ector to contribute effectively to the growth of the local economy, es pecially that the fishing profession has many linkages with sectors of other economic activity.

The manufacturing industries is also considered an important sector, with an endemic city c oefficient of 2.3 in Rashid city, and em ploys $24.8 \%$ of the total workers in the city in 2006, it is expected to increase in the future due to the establishment of $\mathrm{i}$ ndustrial zone a nd increasing in developing some key industries in the food processing, fishing boats, industries related to tourism, the introduction of some furniture manufacture from palm trees, where the growth rate of the annual operating in this sector is $8.1 \%$ during the period 1996 to 2006 and is expected to increase to 3\% during the period 2006 to 2007, which will Provide additional 1002 jobs. This sector is estimated to contribute in the GDP of Rashid city by about 171 million pounds in 2006 . 


\subsection{Supply, facilities and infrastructure of the city}

This section discusses the urban study for the city to stan $\mathrm{d}$ on the current situation of th e city infrastructure represented in the road networks, transportation networks, traffic, drinking water supply, and sanitation, in addition to mechanisms for the disposal of solid waste, the electricity, energy networks and telecommunications

- Road, transportation and traffic networks in Rashid;

- Drinking water supply networks in Rashid;

- Sewage study of Rashid city and its suburbs;

- Electricity and energy sector in Rashid and its suburbs;

- The telecommunications sector in Rashid and its suburbs;

- Mechanisms for solid waste disposal in Rashid city and its suburbs.

\subsection{The current social services study of Rashid city}

Depending on the field visits and compiling information about public services that address the educational, therapeutic, sports, food supply, security, social and administrative services, the most important requirements needed in the future are summarized in the following items

A - Provide educational services to accommodate the expecte $d$ increase in population alongside encouraging the private sector to contribute to the education sector in the city and center of Rashid to provide 7 schools for primary education, 4 for Intermediate education and 4 schools for secondary education.

B - Support treatment services in the city, by establishing a private hospital with a capacity of 150 beds to meet the current deficit and the future needs.

$\mathrm{C}$ - Activate the sports facilities to set up a sports club in Rashid city of 10 acres to attract young people and invest their energies in the sports sector.

D - Stimulate the cultural and recreational services through supporting the city with a proper museum that fits Rashid locally and internationally.

\section{Future development vision and perspective of Rashid developing city}

The second and third stages of preparing the strategic plan for the development of Rashid city, which is limited to three main axes; the first represents the quartet analysis of key issues for the city, the second is the identification of features and objectives for the future vision of the city, and last the third axis that exposes the implementation mechanisms of the General strategic plan of Rashid city.

\subsection{Analysis of the main issues of Rashid city (SWOT Analysis)}

The resources that fulfills the vision of Rashid city is a promising city with a unique location, with gardens and palm trees (more than a million one), the sand dunes on the banks of the Nile, the city also contains many historical places, 14 various historical mosques, 22 houses, the monumental park, and a copy of the Rashid Stone .It also has four touristic hotels, and 1500 acres land dedicated to 
the tourist resort on the shores of Rashid Sea and the Nile, in addition to industrial resources and raw materials for manufacturing. There is a huge fleet of fishing boats in Rashid made in the city, produ cing large quantities of fish suitable for fish preserving industry. As for the working manpower about a quarter of the number of employees in economic sector in the city in 2006, that is over 21 thousand employees (Table 1).

Table 1: $\quad$ SWOT Analysis Table made by the researcher.

\begin{tabular}{|c|c|}
\hline Strength & $\begin{array}{l}1 \text { - Availability of the environmental and archaeological } \\
\text { resources that suit the distinctive tourist activity. } \\
2 \text { - The availability of many sources of raw materials and } \\
\text { labor required for manufacturing industries. } \\
3 \text { - Accessibility of resources and assets well suited to } \\
\text { fishing. } \\
4 \text { - The availability of palm trees wealth. } \\
5 \text { - Many residents are ready to contribute to the } \\
\text { development projects. }\end{array}$ \\
\hline Weakness & $\begin{array}{l}1 \text { - Lack of financial resources earmarked for development. } \\
2 \text {-The deficiency in infrastructure of the development } \\
3 \text { - Weak industry structure, need for modernization } \\
\text { development and High unemployment and poverty. } \\
4 \text { - There are no plans and clear mechanisms for } \\
\text { development. } \\
5 \text { - Lack of local administrative staff that will manage } \\
\text { development effectively. } \\
7 \text { - High proportion of slum dwellers. } \\
8 \text { - Low participation of women in economic activity. }\end{array}$ \\
\hline Opportunities & $\begin{array}{l}\text { 1- Pay attention and support the political leadership. } \\
2 \text { - Placing Rashid on the national tourism map. } \\
3 \text { - The presence of the international coastal road. } \\
4 \text { - The decision to modernize Egyptian industry. } \\
5 \text { - The decision to establish an industrial zone in Rashid. } \\
6 \text { - Liquefy natural gas project. } \\
7 \text { - The willingness of some investors to participate in } \\
\text { development projects. }\end{array}$ \\
\hline Threats & $\begin{array}{l}1 \text { - Waste of potential and resources available if exploited. } \\
2 \text { - Possible loss of political support over time. } \\
3 \text { - Failure to meet the population need with local economy } \\
4 \text { - Aggravate the unemployment problem. } \\
5 \text { - Increase in poverty and low standard of living. } \\
6 \text { - Pollution caused by poor environmental management } \\
7 \text {-Increase populations' displacement for lack of } \\
\text { employment opportunities. } \\
8 \text { - Fishermen migration due to holding back their activity. }\end{array}$ \\
\hline
\end{tabular}




\subsection{Main goal}

The future vision for Rashid city requ ires working to achieve the following general objectives:

1 - Priority to development the leading economic sectors, particularly tourism and manufacturing industries.

2 -Providing all th e facilities and infrastructure to support economic development and the improvement of the city in general.

3 - To improve and protect the eco-system to provide a permanent climate for tourism development, and minimize the side effects of industrial development.

4 - Preparation and training of skilled labor, and administrative effective staff required to development tourism and industrial activities associated with them.

5 - Coordination of efforts between the government and private organization in local development activities.

\subsection{Main objectives for the local economy}

1 - Development of services and tourism activities.

2 - Upgrading the domestic industries, and the development of new ones.

3 - Develop the production of pal $\mathrm{m}$ and take advantage of it to support the tourist activity and the manufacturing sector.

4 - Develop the fisheries sector and benefit from it in supporting tourism and industrial activity.

5 - Upgrading the infrastructure services in support of economic activity.

6 - Work to increase employment rates and reduce unemployment.

7 - Increase interest in training programs to meet the needs of development and modernization of economic activities.

\subsection{The overall objectives of shelter and slums}

1 - Upgrading the residential areas located near Rashid with different housing patterns to improve the living conditions within the existing housing units.

2 - Encouraging the private sector to contribute to the construction of new proposed residential areas depending on the real estate market in Rashid.

3 - The study of promoting the deteriorating residential areas, the replacement and renovation development plans for these areas according to their situations and depending on the successive five-year plans until the target year 2027.

4 - Planning empty and fal low land in accordance with the proposed housing types by general defines of the real estate market housing units.

5 - Directing population growth and sprawl axes in accordance with the general outline toward the west with the support of the current trends of urbanization.

6 - Upgrading slums and informal housing.

7 - Repackaging of slums and informal housing in order to reduce the spread of these areas as well as the availability of some key services. 


\subsection{General goals related to services and infrastructure}

1 - Complete the development of the Corniche Road and some main roads.

2 - Development of internal mass transport, and the establishment of a new Station outside of urban fabric.

3 - Complete feeding drinking water networks in disadvantaged areas.

4 - Strengthening the drinking wate $r$ networks to accommodate the expected population increase until the year 2027.

5 - Completion and development of the sewage networks.

6 - Completion of the electric grid to the disadvantaged areas.

7 - To extend and strengthen the power grid to the northern region.

8 - Providing the educational services to put up with the population increase.

9 - The provision of treatment services.

10 - Revitalization of sports facilities.

11 - Strengthening cultural and recreational services.

\subsection{The strategic plan of Rashid city}

The strategic plan of the existing Rashid city is b ased mainly on the calculated extension of the urban agglomeration to avoid the intrusion on surrounded agricultural land, also absorbing the expected population increase with the required extend, in addition to developing the basic infrastructure networks such as, the roads and t ransportation networks, the drinking water and sewage network, solid waste disposal network, the electricity, power and communication network. Also the plan aims to solve all environmental problems and availability of the basic services like educational, therapeutic and social services also sports, commercial, administrative, security service, and insuring a ju stice distribution of these services through the current and future urban agglomeration.

The plan was also concerned with the necessity to maintain the historical city given that Rashid is con sidered the second richest city in Egypt whence the Islamic monuments, which mainly exists in 3 streets they are Dahaleez El-Molk street (Fish Market), Sidi El-Mahaly street and El -Sheikh Kandeel street in addition to kayet Bay Castle which is located $8 \mathrm{kms}$ away from the city, where Rosetta stone was originally discovered and decoded.

\section{Sustainability}

"Sustainability meets the needs of the present without compromising the ability of future generations to meet their own needs." - United Nations World Commission on Environment and Development.

Environmentally sustainable urbanization requires that:

- Greenhouse gas emissions are reduced and serious climate change mitigation and adaptation actions are implemented.

- Urban sprawl is minimized and more compact towns and cities serv ed by public transport are developed.

- Non-renewable resources are sensibly used and conserved. 
- The waste produced is recycled or disposed of in ways that do not damage the wider environment.

- The ecological footprint of towns and cities is reduced.

Only by dealing with urbanization within regional, national and even international planning and policy frameworks can these requirements be met.

Priorities and actions for economic sustainability of towns and cities sh ould focus on local economic development, which entails developing the basic conditions needed for the efficient operation of economic enterprises. The social aspects of urbanization and economic development must be addressed as part of the sustainable urbanization agenda (UN-Habitat [7]).

\section{Preparation of the action and the executive plans}

The last part of the paper aims to comprehensively review the steps of preparing the outline, action and executive plans, which had been counted in four main axes where the first review the field work of the future extension regions of the city, The second displays how to plan the future extension areas with development partners while the third deals with re-planning projects of slums and degraded planning areas of the city and then concludes with a list of the obstacles facing the implementation and effectiveness of the city's Executive plans.

\subsection{Check the field survey for future extension areas}

The detailed plan is interested in the determine of areas will be treated to achieve the goals of the Strategic Plan which was approved, issued ministerial decisions on it accordingly and adopting the proposed urban limits, in which it is restricted to those zones in the future extension areas of slums and degraded planning areas.

The Consultant Office through a specialized office in the cadastral process of an inspection for the slums and the future extension areas in order to identify the changes that have occurred in the period between the preparation of the Strategic Plan to the period of the preparation of the detailed plans, and especially after the events of the revolution on January 25, which spread the random building phenomenon.

\subsection{Planning areas for future extension with development partners}

The importance of the future extension areas is owed to the planning of these areas, in accordance with the approved strategic plan to provide residential areas in assessment percentages to cover the current deficit and the future projects requirement in addition to ex ecute the public, remedial, education, sports and social services in the scheme provided sites for the approved strategic plan.

Meeting with the land owners for future sprawl in the presence of each of (the Regional Centre II - the territory of Alexandria - of the General Authority for Urban Planning, Ministry of Housing, Utilities and Urban Development), representatives from the Department of Urban Planning of Elbeihaira province, 
the Department of Ur ban Planning of the city of R ashid, and the Consultant Office to coordinate betwee n all parties who are called "developm ent partners" and explaining the detailed planning project for those lands.

Urban Extension regions are planned as residential areas with all available services in accordance with the strategic scheme and in according to the planning principles and standards agreed on and thus public services percentage can be identified of the total land allocated to the urban future extension, therefore this figure can be deducted equally from the landowners, assign the servic es with their knowledge and in acc ordance to their common agreement for the services places on their lands.

\subsection{Re-planning of slums and degraded areas of the city}

Upgrading slums and degraded areas planning projects are based on the accurate field survey that address the aspect of building, construction and land uses in addition to the study of social and economic development of those areas in order to identify aspects of the deficit in public services and the most important educational services, therapeutic and health issues, also the curre nt state of infrastructure networks represented by the failure of these networks in terms of functional or deprivation that the slums and degraded areas suffer fro $m$ when it comes to road networks, traffic, transportation, drinking water, sanitatio n, electricity, telecommunications and gas.

A plan is developed to deal with slums and degraded areas, in which the best method is determined that can be $\mathrm{f}$ ollowed of replacement, renovation or rehabilitation of existing buildings or merger between the two ways, bearing in mind the situation where the introduction of networks to those areas, including disadvantaged ones or raise the efficiency of these networks if they exist.

\subsection{Obstacles facing the implementation and effectiveness of the detailed plans of the city}

According to the multiple applications in the preparation of strategic plans of Egyptian cities, these plans face m any obstacles that increase the la rge gap between strategic plans, and detailed ones, and the implementation mechanisms impede those plans, where these obstacles can be limited in the following

- Difficulty to deal with private property while assigning the public services;

- Passivity and lack of cooperation by local administrations;

- Difficulty of finding the land owners (private property);

- Lack of awareness and conviction of the important detailed plan;

- Conflict of laws and regulations of building with strategic plans.

\section{Conclusion}

The preparation of strategic urban plans is b uilt on a li mited set of well connected principles, of which the most important and far reaching is sustainable development. It seek s to strengthen the political sustainability of leaders and social sustainability by including vulnerable people at every step of the process, 
economic sustainability of the projects, and environmental sustainability of resources used (Khalifa [5]); they are also characterized by:

- Flexible rather than end-state oriented fixed action and implementation oriented through links to budgets, projects and ci ty-wide or regional infrastructure.

- Stakeholder or community driven rather than only expert driven.

- Occasionally linked to political terms of office.

- Contain objectives reflecting emerging urban concerns, for example, city global positioning, environmental protection, sustainable development, social inclusion and local identity, play an integrative role in policy formulation and in urban management by encouraging government departments to coordinate their plans in space.

\section{Abbreviation}

- The GOPP is the national Egyptian authority responsible for the planning process. It was established in 1973, and since then has been responsible in formulating urban development general policy, preparing plans and programs for urban development at the national, regional and governmental levels, revising and approving of urban plans at local level and preparing planning guidelines and the coordination of planning processes all over Egypt

- EHAP: Egyptian House for Architecture and Planning - a n Egyptian consultant firm; one of many firms entrusted to pursue the strategic and detailed plan of the Egyptian cities.

\section{References}

[1] UN-Habitat, Planning sustainable cities, global report on human settlements, London. Sterling, VA: Un ited Nations Human Settlements Program (2009).

[2] De Graaf, R. S., and Dewulf, G. P. M. R. "Applying the lessons of strategic urban planning learned in the developing world to the Netherlands: a case study of three industrial area development projects". Habitat International (2010).

[3] GOPP. The national urban development plan in the Arab Republic of Egypt. Ministry of Housing, Utilities and Urban Development (2009).

[4] GOPP, The Regional Development - The Development Strategies of the Republic Governorate. Ministry of Housing, Utilities an d Urban Development (2008). Arabic Reference.

[5] Khalifa, M.A., "A Critical Review on Current Practices of the Monitoring and Evaluation in the Preparation of Strategic Urban Plans within the Egyptian Context." Habitat International (2011).

[6] GOPP and EHAP, General Strategic and Detailed Planning for Rashid City 2027, Ministry of Housing, Utilities and Urban Development (2009). Arabic Reference.

[7] UN-Habitat and Department for International Development (DFID) (2002) Chapter 4, pp. 18-27. 